\title{
Occupational risk of exposure to methicillin-resistant Staphylococcus aureus (MRSA) and the quality of infection hygiene in nursing homes
}

\author{
Pil Uthaug Rasmussen $(\bowtie)^{1}$, Katrine Uhrbrand ${ }^{1}$, Mette Damkjær Bartels ${ }^{2}$, Helle Neustrup ${ }^{2}$, Dorina Gabriela \\ Karottki $^{1,3}$, Ute Bültmann ${ }^{1,4}$, Anne Mette Madsen ${ }^{1}$ \\ 1 National Research Centre for the Working Environment, Lersø Parkallé 105, 2100 Copenhagen Ø, Denmark \\ 2 Department of Clinical Microbiology, Hvidovre Hospital, Kettegård Allé 30, 2650 Hvidovre, Denmark \\ 3 The Danish Working Environment Authority, Landskronagade 33, 2100 Copenhagen, Denmark \\ 4 University Medical Center Groningen, Department of Health Sciences, Community \& Occupational Medicine, University of Groningen, \\ 9700 Groningen, The Netherlands
}

\section{H I G H L I G H T S}

- Staff members were not colonised with MRSA.

- But staff were exposed to MRSA from air, sedimented dust and surfaces.

- MRSA was found in the rooms of MRSAcolonised residents but not in common areas.

- Staff worry about MRSA and spreading it to other residents, family, and acquaintances.

- The use of protective eyewear and facemasks could be improved.

\section{A R T I C L E I N F O}

Article history:

Received 6 July 2020

Revised 4 September 2020

Accepted 7 October 2020

Available online 13 November 2020

\section{Keywords:}

Antibiotic resistance

Airborne MRSA

Bioaerosols

Healthcare-associated infections

Healthcare worker

Occupational health

\section{GR A P H I C A B S R A C T}

\section{Exposure to MRSA in nursing homes}

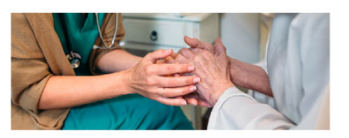

MRSA found in

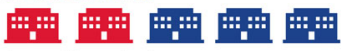

2 out of 5 nursing homes

Staff were exposed to MRSA in residents' rooms

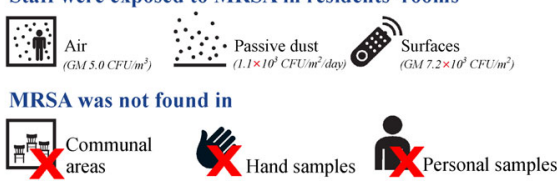

A B S T R A C T

Methicillin-resistant Staphylococcus aureus (MRSA) is an increasing health concern across the globe and is often prevalent at long-term care facilities, such as nursing homes. However, we know little of whether nursing home staff is exposed to MRSA via air and surfaces. We investigated whether staff members at nursing homes are colonised with and exposed to culturable MRSA, and assessed staff members' self-reported knowledge of MRSA and compliance with infection hygiene guidelines. Five nursing homes with MRSA positive residents were visited in Copenhagen, Denmark. Personal bioaerosol exposure samples and environmental samples from surfaces, sedimented dust and bioaerosols were examined for MRSA and methicillin-susceptible $S$. aureus (MSSA) to determine occupational exposure. Swabs were taken from staffs' nose, throat, and hands to determine whether they were colonised with MRSA. An online questionnaire about MRSA and infection control was distributed. No staff members were colonised with MRSA, but MRSA was detected in the rooms of the colonised residents in two out of the five nursing homes. MRSA was observed in air ( $n=4$ out of 42 , ranging from 2.9-7.9 CFU/m $\left.{ }^{3}\right)$, sedimented dust $\left(n=1\right.$ out of $\left.58,1.1 \times 10^{3} \mathrm{CFU} / \mathrm{m}^{2} / \mathrm{d}\right)$, and on surfaces $\left(n=9\right.$ out of $113,0.04-70.8 \mathrm{CFU} / \mathrm{m}^{2}$ ). The questionnaire revealed that half of the staff members worry about spreading MRSA to others. Identified aspects for improvement were improved availability and use of protective equipment, not transferring cleaning supplies (e.g., vacuum cleaners) between residents' rooms and to reduce worry of MRSA, e.g., through education.

C The Author(s) 2020. This article is published with open access at link.springer.com and journal.hep. com.cn

$\triangle$ Corresponding author

E-mail: pur@nfa.dk

Special Issue - Bioaerosol, Environment and Health (Responsible Editors: Can Wang, Jungho Hwang, Jingkun Jiang \& Maosheng Yao) 


\section{Introduction}

More than 40000 seniors (i.e. over 65 years) are currently residing in nursing homes in Denmark (Sundheds- Og $尹$ ldreministeriet, 2016). This number is expected to increase in the coming years (Danmarks Statistik, 2020). In Denmark, half of the residents have one or more chronic disease and over two thirds have dementia (Sundheds- Og Ældreministeriet, 2016). The residents also have an increased use of pharmaceuticals, are more in contact with doctors, and have more admissions to the hospital than others of the same age who do not live in nursing homes (Sundheds- Og Ældreministeriet, 2016). These factors are contributing to the typically high prevalence of multidrug-resistant microorganisms and MRSA in nursing homes (Bradley, 1999; Stone et al., 2008; Garazi et al., 2009). We therefore need more information on the risk of occupational exposure to multidrug-resistant microorganisms for healthcare workers.

Multidrug-resistant microorganisms, such as methicillin-resistant Staphylococcus aureus (MRSA), a bacterium resistant to many of the antibiotics typically used for treatment, is a worldwide concern (CDC, 2013; WHO, 2014; DANMAP, 2018). MRSA accounts for more than half of $S$. aureus infections worldwide (WHO, 2014), but in Denmark, the incidence level is low, with almost 4000 new cases in 2018 constituting only $1.6 \%$ of $S$. aureus bacteraemia cases (DANMAP, 2018). To avoid spread, adequate precautions have to be taken when healthcare personnel are interacting with MRSA-infected or colonised individuals (Calfee et al., 2014). In hospitals, this includes isolation of patients in their rooms (Calfee et al., 2014). In Danish nursing homes, isolation of residents with MRSA is not allowed unless they have a respiratory infection. In addition, rooms are rented to the residents who have some autonomy in their own rooms, while healthcare and cleaning personnel assist with personal care and cleaning. Residents are fully integrated into everyday activities at the nursing home and in common areas, and this may facilitate MRSA transmission and increase the exposure of staff members in nursing homes when interacting directly and indirectly with individuals colonised with MRSA. Nevertheless, little is known about the degree to which nursing home staff members are exposed to, colonised with, or infected with methicillin-susceptible $S$. aureus (MSSA) and MRSA, especially in regards to airborne MRSA, which for many may be an overlooked transmission route (Kozajda et al., 2019). According to the MRSA guidelines from the Danish Health Authority, extended hygiene practices have to be met when taking care of the infected or colonised residents and when cleaning their room (The Danish Health Authority, 2016). If adequate hygiene practices are not met, there may be a higher risk of exposure to staff members, or if staff members are colonised with MRSA they can act as vectors to other residents or colleagues (Albrich and Harbarth, 2008). We therefore need i) more information on the transfer of MRSA via air and surfaces within nursing home settings and the risks it poses for the staff, and ii) to understand the staff's experience with MRSA and compliance with infection hygiene guidelines. To answer these questions five nursing homes, which had residents colonised with MRSA were visited twice in the Capital Region of Denmark. Staff members were screened for MRSA, and bioaerosol, sedimented dust, and surface samples were taken. Furthermore, a questionnaire about MRSA and hygiene practices was sent to nursing home staff members in four of the nursing homes. The study aimed at answering whether MRSA is present on the hands and in the airways of nursing home staff, whether nursing home staff is exposed to MRSA or MSSA during their work in both the colonised residents' rooms and in common areas, and what the level of knowledge and experience of staff members to MRSA and infection hygiene is.

\section{Materials and methods}

\subsection{Sampling location and participants}

Sampling was carried out from October 2017 to June 2018 at five nursing homes (A-E) in the Capital Region of Denmark with residents known to be MRSA-colonised. The nursing homes were selected because they had at least one MRSA positive resident who was monitored at the MRSA Knowledge Center at Hvidovre Hospital. Each nursing home was visited on two separate occasions with 14 days apart and 52 staff members in different job functions participated in the study. A total of 79 personal exposure assessments were conducted as some staff members participated on both of the two sampling days. Four to eleven personal assessments were done per sampling day, and of the 79 assessments conducted, 8 $(10 \%)$ were on nurses, $37(47 \%)$ were on social and healthcare assistants, $15(19 \%)$ were on social and healthcare helpers, 7 (9\%) were on cleaning assistants, and $12(15 \%)$ were on staff with other job titles. Participation was voluntary and all staff members and residents colonised with MRSA signed a consent form before entering the project. The resident had to give both oral and written consent to have MRSA samples taken from the environment of their room. Ethical approval was applied for, but the National Committee on Health Research Ethics decided an approval was not needed for the types of samples taken (swabs and bioaerosol measurements), as only microorganisms but not biological material was taken from the participants. 


\subsection{MRSA screening of staff}

Staff members were screened for MRSA in the nose, throat and on their hands at the beginning and end of the working day. Sampling was done using the eSwab transport system (eSwab; Copan, Brescia, Italy) which consists of a flocked nylon swab and $1 \mathrm{ml}$ transport medium. Nasal samples were taken from the anterior nares by rotating the same swabs in each nostril. Throat samples were obtained by swabbing the palatopharyngeal arch and tonsils on both sides. Hand samples were collected by rotating the eSwabs axially and laterally in a zigzag motion over the entire surface of each palm, using the same swabs on both right and left hand. After sampling, all swabs were transferred to their container, stored cold $\left(4^{\circ} \mathrm{C}\right)$, and processed within 24 hours of sampling. Hand samples were vortexed for $2 \mathrm{~min}$, plated in serial-dilutions on chromogenic SaSelect agar (SA; Biorad, Solna, Sweden) and incubated at $37^{\circ} \mathrm{C}$ for 48 hours. Eswabs from nose and throat samples were inoculated into MRSA enrichment broth (TSB containing $2.5 \% \mathrm{NaCl}, 3.5 \mathrm{mg} / \mathrm{L}$ cefoxitin, and $20 \mathrm{mg} / \mathrm{L}$ aztreonam; (Böcher et al., 2010)) and incubated overnight at $35^{\circ} \mathrm{C}$. Ten $\mu 1$ of broth was then inoculated onto a selective MRSA plate (Brilliance MRSA 2 agar, Oxoid, Thermo Fisher Scientific) and an unselective 5\% Danish Blood agar plate and incubated overnight. Colonies suggestive of $S$. aureus were identified using matrix-assisted laser desorptionionisation time-of-flight (MALDI-TOF) mass spectrometry (MS) and their susceptibility to cefoxitin $(30 \mu \mathrm{g})$ was determined. For isolates resistant to cefoxitin according to EUCAST breakpoints, the presence of mecA or mec $\mathrm{C}$ was confirmed by an in-house PCR.

\subsection{Exposure to MRSA}

To collect bacteria from the inhalation zone of the nursing home staff, personal air samplers (Gesamtstaubprobenahme sampler (GSP), CIS, BGI Inc., Waltham, MA, USA) mounted with a $37 \mathrm{~mm}$ polycarbonate filter (PC, pore size $1.0 \mu \mathrm{m}$, Main Manufacturing, Grand Blanc, MI, USA) and a flow rate of $3.5 \mathrm{~L} / \mathrm{min}$ were used. The personal GSP samplers, connected to pumps worn in a backpack, were placed in the breathing zone of the participants. The GSP was chosen, as it samples inhalable particles (airflow $3.5 \mathrm{~L} / \mathrm{min}$ ), and as it has been described to have a good sampling efficiency (Kenny et al., 1999). The personal air sampling was performed during an entire working day while the nursing home staff performed normal job tasks. The average personal air sampling period was $315 \mathrm{~min}$.

To collect air samples during specific work tasks, e.g. while providing assistance to the resident colonised with MRSA or during cleaning of their residence, stationary short-term air sampling was used. For this, a GSP sampler with a PC filter was placed at a fixed height of $1.5 \mathrm{~m}$ and sampled for $20 \mathrm{~min}$ at a flow rate of $3.5 \mathrm{~L} / \mathrm{min}$. In addition, stationary air sampling was performed by collecting bacteria directly on SA agar using a six-stage Andersen Cascade Impactor (ACI; N6, Thermo Fisher Scientific Inc. Waltham, MA, USA) with a flow rate of $28.3 \mathrm{~L} / \mathrm{min}$ measuring for an average of 10 minutes and at a height of 1 $\mathrm{m}$. ACI samples were stored in a cool box and incubated directly at $37^{\circ} \mathrm{C}$ for $48 \mathrm{~h}$ upon return to the laboratory.

Electrostatic dust cloths (EDCs; ZEEMAN, Alphen, Holland, surface exposure area of $0.0209 \mathrm{~m}^{2}(19 \mathrm{~cm} \times 11$ $\mathrm{cm})$ ) were used for long-term passive sampling of sedimented dust. On each sampling visit, EDCs were placed on an open surface and dust allowed to settle for $7 \mathrm{~d}$. EDCs were placed in the residences of the MRSAcolonised individuals, common areas, corridors in common areas, staff changing rooms, staff offices, and laundry rooms at a height ranging from $0.7-1.8 \mathrm{~m}$. In total, 11-12 EDCs were placed per nursing home.

An outdoor stationary reference measurement was taken at every sampling. Outdoor references were taken with a GSP placed at a height of $1.5 \mathrm{~m}$. The average sampling time of the reference measurements was 385 min. Temperature and relative humidity were measured inside and outside the nursing homes during sampling using Tinytag Plus Data Loggers (Germini Data Loggers, United Kingdom; Table S1).

Bacteria from all GSP filters and EDC cloths were extracted in 5 and $20 \mathrm{~mL}$ of pyrogen-free water containing $0.85 \% \mathrm{NaCl}$ and $0.05 \%$ Tween 80 , respectively. Staphylococci bacteria were enumerated by dilution plating and incubation on SA agar at $37^{\circ} \mathrm{C}$ for $48 \mathrm{~h}$.

Environmental surface sampling of armrests, tables, door handles, light switches, and TV remotes was conducted in the MRSA individuals' residences and in the common areas of the nursing homes (on average 10 swabs in total of each type, both in residences and common rooms), and surface samples were furthermore taken from the bed rails of the resident colonised with MRSA $(n=10)$. Sampling was done using eSwabs by rotating the swab axially and laterally in a zigzag motion over a surface area of approximately $100 \mathrm{~cm}^{2}$. Samples were stored and processed as described for the hand swabs.

\subsection{Identification and molecular characterization of MRSA isolates}

Presumptive $S$. aureus isolates were recognized based on morphological appearance on SA media. Identification was performed on all the presumptive S. aureus isolates from all samples using MALDI-TOF MS as described in (Feld et al., 2018). All S. aureus isolates from exposure samples were tested for methicillin resistance by sub cultivation on Brilliance MRSA 2 agar for $24 \mathrm{~h}$ at $37{ }^{\circ} \mathrm{C}$. One presumptive MRSA isolate from each sample was selected for molecular verification and were confirmed to be MRSA 
by an in-house multiplex PCR targeting the genes mecA, $m e c \mathrm{C}$, nuc and $f e m \mathrm{~A}$. MRSA isolates were then whole genome sequenced on an Illumina MiSeq and assembled as previously described (Bartels et al., 2015). cgMLST was performed using the Ridom SeqSphere software and the isolates were compared to the whole genome sequenced isolates from the MRSA colonised patients from the specific nursing home in order to confirm whether the environmental MRSA was identical to the isolate of the patient.

\subsection{Questionnaire}

A self-administered questionnaire was distributed among the staff members of four nursing homes (A, B, C, E) covering approximately 100 questions on knowledge regarding MRSA and infection hygiene. Due to time constraints at the nursing home, staff members at nursing home $\mathrm{D}$ did not participate. The questionnaire inquired about the participant's background, knowledge of and experience with MRSA and infection hygiene, compliance with infection hygiene guidelines, and opinions on the consequences of working with residents with MRSA. The questionnaire was sent to 161 nursing home staff members, and 74 respondents answered the questionnaire (46\% response rate). Both complete $(n=51)$ and partial $(n=23)$ completions were included in the analyses. Due to the length of the questionnaire, we only report key findings in the Results section, but a full description can be found in the Supplementary Information (Results S1, Tables S2S6).

\subsection{Data and statistical analyses}

Bacterial concentrations were calculated as geometric mean (GM) concentration per $\mathrm{m}^{3}$ of air $\left(\mathrm{CFU} / \mathrm{m}^{3}\right)$ for GSP and ACI air samples, as GM concentration per $\mathrm{m}^{2}$ per day $\left(\mathrm{CFU} / \mathrm{m}^{2} / \mathrm{d}\right)$ for EDC samples, as GM concentration per $\mathrm{cm}^{2}\left(\mathrm{CFU} / \mathrm{cm}^{2}\right)$ for surface samples, and GM concentration per hands (CFU/hands) for hand samples. Limits of detection was on average: personal GSP $=8.2$ $\mathrm{CFU} / \mathrm{m}^{3}$, GSP during tasks $=47.6 \mathrm{CFU} / \mathrm{m}^{3}, \mathrm{ACI}$ during tasks $=2.9 \mathrm{CFU} / \mathrm{m}^{3}, \mathrm{EDC}=91.1 \mathrm{CFU} / \mathrm{m}^{2} / \mathrm{d}$, eSwabs were $0.04 \mathrm{CFU} / \mathrm{cm}^{2}$ for surfaces and $8.3 \mathrm{CFU} /$ hands for hand swabs.

In order to investigate the impact of nursing home and job group on responses to the questionnaire, we ran linear mixed effect models with nursing home, job and their interaction as fixed effects. For questions where respondents had to give a rating of e.g. their knowledge, the answers were given on a scale from 1-5, and otherwise answers were treated as categories. All analyses were conducted in R v.3.5.3 (R. Core Team, 2019), using packages lme4 v. 1.1-24 and car v. 3.0-3 (Fox and Weisberg, 2011; Bates et al., 2014).

\section{Results}

\subsection{Exposure to MRSA}

MALDI-TOF identification was attempted on bacterial isolates from the stationary ACI air samples, stationary and

Table 1 Staphylococcus aureus and methicillin-resistant S. aureus (MRSA) found during screening of staff members and the exposure to MRSA in air, surface and sedimented dust samples. Percentages calculated based on the total number of samples

\begin{tabular}{|c|c|c|c|c|c|c|c|}
\hline \multirow{2}{*}{ Sample group } & \multirow{2}{*}{$\begin{array}{c}\text { Total number } \\
\text { of samples }\end{array}$} & \multicolumn{3}{|c|}{ S. aureus positive samples } & \multicolumn{3}{|c|}{ MRSA positive samples } \\
\hline & & $\%$ & $n$ & Concentration & $\%$ & $n$ & Concentration \\
\hline \multicolumn{8}{|l|}{ MRSA screening of staff } \\
\hline Nasal swab & 158 & - & - & & 0 & 0 & \\
\hline Throat swab & 156 & - & - & & 0 & 0 & \\
\hline Hand swab & 158 & 10.8 & 17 & $10-150 \mathrm{CFU} / \mathrm{hand}$ & 0 & 0 & \\
\hline Total of all screening samples & 472 & $3.6 \%$ & 17 & & 0 & 0 & \\
\hline \multicolumn{8}{|l|}{ Exposure to MRSA } \\
\hline Personal GSP air sample & 79 & 15.2 & 12 & 7.3-201.9 CFU $/ \mathrm{m}^{3}$ & 0 & 0 & \\
\hline Stationary GSP air sample & 46 & 6.5 & 3 & 285.7-1857.1 CFU $/ \mathrm{m}^{3}$ & 0 & 0 & \\
\hline 6-stage ACI stationary air sample & 42 & 21.4 & 9 & $2.9-173.1 \mathrm{CFU} / \mathrm{m}^{3}$ & 9.5 & 4 & $2.9-7.9 \mathrm{CFU} / \mathrm{m}^{3}$ \\
\hline EDC sedimented dust sample & 58 & 8.6 & 5 & $91.1-1093.6 \mathrm{CFU} / \mathrm{m}^{2} / \mathrm{d}$ & 1.7 & 1 & $1.1 \times 10^{3} \mathrm{CFU} / \mathrm{m}^{2} / \mathrm{d}$ \\
\hline Surface sample & 113 & 23.6 & 26 & $0.04-70.8 \mathrm{CFU} / \mathrm{cm}^{2}$ & 8.2 & 9 & $0.04-70.8 \mathrm{CFU} / \mathrm{cm}^{2}$ \\
\hline Total of all exposure samples & 338 & $16.3 \%$ & 55 & & $4.1 \%$ & 14 & \\
\hline Stationary GSP outdoor air reference & 10 & 0 & 0 & & 0 & 0 & \\
\hline
\end{tabular}

Staff members were screened for MRSA at the start and end of the working day. Incidence of $S$. aureus was not determined for nasal and throat samples. ACI $=$ stationary six-stage Andersen Cascade Impactor, GSP = stationary Gesamtstaubprobenahme sampler, EDC = electrostatic dust cloth. Each 6-stage ACI stationary air sample was grown on six chromogenic SaSelect agar plates, but here all six plates are presented as one sample. 
personal GSP air samples, outdoor reference air samples, surfaces samples, and hand swabs. In total, $423 \mathrm{~S}$. aureus isolates were identified, and these were found in 72 out of the 496 samples examined for $S$. aureus (Table 1). Of the $S$. aureus isolates, $25.3 \%$ (107 isolates) were presumed to be methicillin resistant. These MRSA isolates were found in a total of 14 samples, consisting of 4 stationary ACI air samples, 1 EDC sample, and 9 surface samples (Table 1). MRSA was not detected in nose, throat or hand swabs from the staff members (neither at the beginning nor at the end of the working day), in any of the stationary or personal GSP air samples, nor in references air samples (Table 1).

Overall, MRSA was detected in the colonised-residents' room but not in common areas, and while MSSA was present at all nursing homes, MRSA was only detected in two of the five nursing homes. Whole genome sequencing showed that the MRSA spa types (t) and multilocus sequence types (ST) (t3841/ST672 and t223/ST22) found at each nursing home matched that of the infected resident at that home (Fig. 1).

(a)

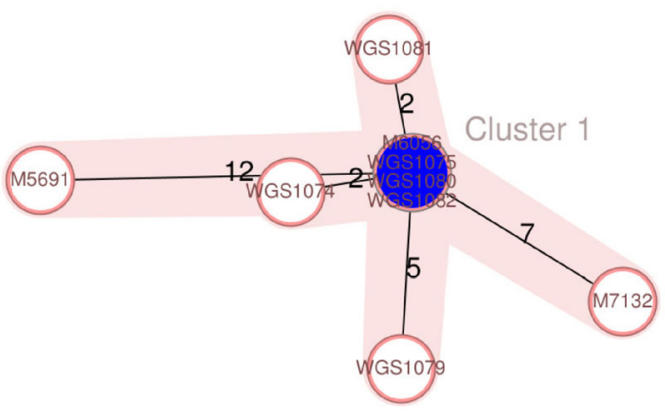

(b)

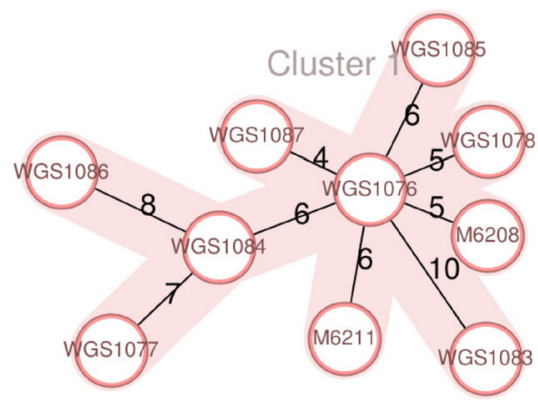

Fig. 1 Whole genome clustering of methicillin-resistant $S$. aureus (MRSA) isolates at the two nursing homes (a) and (b) were MRSA was detected. MRSA isolates starting with M is from the colonised residents, while isolates starting with WGS are from surface and air samples collected at the nursing home.

Air and sedimented dust samples showed that the nursing home staff members were exposed to MRSA in the air of the MRSA-colonised resident's room (Table 1-2), whereas MSSA was detected in all sample types and in both the common areas and in the residences. MRSA was found during specific work tasks: during personal care tasks, cleaning of floors, and in the background air measurements (Table 2). MRSA was observed in particles in the size range of $4.7 \mu \mathrm{m}$ and above.

MSSA was found on surfaces both in common areas and the colonised residents' room (Table 3). However, MRSA was only detected in the room of the resident colonised with MRSA on armrests, bed rails, TV-remotes, and on the door handles (Table 3).

\subsection{Knowledge of MRSA and infection hygiene}

The majority of respondents (97\% and $77 \%$, respectively) had heard of and reported their knowledge about MRSA as good, very good or excellent (Figs. 2(a)-2(b)), however, knowledge of MRSA differed among job groups $\left(\mathrm{F}_{6,42}=\right.$ 3.67, $P=0.008$; Fig. 2(c)). Most respondents $(83 \%)$ similarly rated their knowledge of infection hygiene as good, very good or excellent (Fig. 3(a)), though this again differed among job groups $\left(\mathrm{F}_{6,49}=3.67, P=0.029\right.$; Fig. 3 (b)). Thirty-eight percent of respondents had heard of but not read the 'Guideline for prevention of spread of MRSA' from the Danish Health Authority, and 21\% had not heard of it. Ninety percent reported that they always or mostly always followed the infection hygiene guidelines, but this differed among job groups and nursing homes (a significant interaction effect; $F_{12,36}=2.14, P=0.039$ ). Eighty-one percent reported that their workplace as a whole always or almost always followed the guidelines. The majority of the respondents reported easy access to personal protective equipment such as gloves and protective clothing. However, protective eyewear (incl. visors) and facemasks (surgical masks and respirators) seemed to be less easily available. Around $40 \%$ and $10 \%$ of the respondents reported that they did not have easy access to protective eyewear and facemasks, respectively. The level of easy access differed among nursing homes (protective eyewear: $\mathrm{F}_{3,36}=2.27, P=0.097$; facemasks: $\left.\mathrm{F}_{3,36}=7.94, P<0.001\right)$. For staff with care tasks, facemasks was used most of the time when there was a risk of splashes and sprays of bodily fluids, however a large group (19\%) stated that they never use it. Similarly, $50 \%$ said they never use protective eyewear in similar situations. Cleaning supplies (e.g., vacuums) sometimes gets transferred from the MRSA residents' room to other places of the nursing home (15\% state it always happens and $8 \%$ that it sometimes happens). Respondents reported that they are a lot or very much $(30 \%)$ worried about contracting MRSA, a lot or very much $(49 \%)$ worried about bringing MRSA from work to family and acquaintances, and a lot and very much (45\%) worried about being the cause of transfer of MRSA to other residents in the nursing home. Whether contracting MRSA would have a negative influence on respondents' social lives, $52 \%$ 
Table 2 Potential exposure to Staphylococcus aureus and methicillin-resistant S. aureus (MRSA) in air samples during specific work tasks conducted in the room of the MRSA-colonised resident. Shown are samples positive for S. aureus and MRSA

\begin{tabular}{|c|c|c|c|c|c|c|c|}
\hline \multirow[b]{2}{*}{ Work task } & \multirow{2}{*}{$\begin{array}{c}\text { Total number of } \\
\text { samples }\end{array}$} & \multicolumn{3}{|c|}{ S. aureus positive samples } & \multicolumn{3}{|c|}{ MRSA positive samples } \\
\hline & & $\begin{array}{c}\mathrm{GM} \\
\left(\mathrm{CFU} / \mathrm{m}^{3}\right)\end{array}$ & $\begin{array}{c}\text { Range } \\
\left(\mathrm{CFU} / \mathrm{m}^{3}\right)\end{array}$ & $n$ & $\begin{array}{c}\mathrm{GM} \\
\left(\mathrm{CFU} / \mathrm{m}^{3}\right)\end{array}$ & $\begin{array}{c}\text { Range } \\
\left(\mathrm{CFU} / \mathrm{m}^{3}\right)\end{array}$ & $n$ \\
\hline \multicolumn{8}{|l|}{$\overline{\mathrm{ACI}}$} \\
\hline Personal care & 6 & 21.1 & $8.9-56.5$ & 2 & 7.9 & - & 1 \\
\hline Cleaning of surfaces $\&$ fomites & 9 & 134.3 & - & 1 & - & - & 0 \\
\hline Cleaning of floors & 6 & 4.8 & $3.5-7.9$ & 3 & 5.6 & $3.9-7.9$ & 2 \\
\hline Bed making & 2 & - & - & 0 & - & - & 0 \\
\hline Nursing tasks & 2 & - & - & 0 & - & - & 0 \\
\hline Background; MRSA residence & 8 & 22.6 & $2.9-173.1$ & 2 & 2.9 & - & 1 \\
\hline Background; Common area & 9 & 3.5 & - & 1 & - & - & 0 \\
\hline \multicolumn{8}{|l|}{ GSP } \\
\hline Personal care & 9 & 285.7 & - & 1 & - & - & 0 \\
\hline Cleaning of surfaces $\&$ fomites & 5 & - & - & 0 & - & - & 0 \\
\hline Cleaning of surfaces, fomites $\&$ floor & 4 & 1857.1 & - & 1 & - & - & 0 \\
\hline Cleaning of floors & 4 & - & - & 0 & - & - & 0 \\
\hline Bed making & 2 & - & - & 0 & - & - & 0 \\
\hline Nursing tasks & 2 & - & - & 0 & - & - & 0 \\
\hline Other (marking of clothes) & 1 & - & - & - & - & - & \\
\hline Background; MRSA residence & 8 & 571.4 & - & 1 & - & - & 0 \\
\hline Background; common area & 11 & - & - & 0 & - & - & 0 \\
\hline Outdoor GSP reference & 10 & - & - & 0 & - & - & 0 \\
\hline
\end{tabular}

Geometric means (GM), ranges, and number (n) of positive $S$. aureus and MRSA samples. A hyphen is listed where no positive samples were observed or for ranges when only one positive sample was found. ACI = stationary six-stage Andersen Cascade Impactor, GSP = stationary Gesamtstaubprobenahme sampler. Values from ACI samples are sums of all the six stages.

Table 3 Surface samples found positive for Staphylococcus aureus and methicillin-resistant S. aureus (MRSA) in the residences of the MRSAcolonised individuals and in the common areas of the nursing homes

\begin{tabular}{|c|c|c|c|c|c|c|c|c|c|c|c|c|c|c|}
\hline \multirow{3}{*}{ Sampling point } & \multicolumn{7}{|c|}{ Residence of MRSA-colonised individual } & \multicolumn{7}{|c|}{ Common area } \\
\hline & \multirow{2}{*}{$\begin{array}{c}\text { Number of } \\
\text { samples }\end{array}$} & \multicolumn{3}{|c|}{$\frac{\text { S. aureus }}{\text { positive samples }}$} & \multicolumn{3}{|c|}{$\begin{array}{l}\text { MRSA positive } \\
\text { samples }\end{array}$} & \multirow{2}{*}{$\begin{array}{c}\text { Number of } \\
\text { samples }\end{array}$} & \multicolumn{3}{|c|}{$\frac{\text { S. aureus }}{\text { positive samples }}$} & \multicolumn{3}{|c|}{$\begin{array}{l}\frac{\text { MRSA positive }}{\text { samples }} \\
\text { a }\end{array}$} \\
\hline & & $\%$ & $n$ & $\begin{array}{c}\mathrm{GM} \\
(\mathrm{CFU} \\
\left./ \mathrm{cm}^{2}\right)\end{array}$ & $\%$ & $n$ & $\begin{array}{c}\mathrm{GM} \\
(\mathrm{CFU} \\
\left.“ / \mathrm{cm}^{2}\right)\end{array}$ & & $\%$ & $n$ & $\begin{array}{c}\mathrm{GM} \\
(\mathrm{CFU} / \\
\left.\mathrm{cm}^{2}\right)\end{array}$ & $\%$ & $n$ & $\begin{array}{c}\mathrm{GM} \\
(\mathrm{CFU} / \\
\left.\mathrm{cm}^{2}\right)\end{array}$ \\
\hline Armrest & 10 & 30 & 3 & 0.53 & 30 & 3 & 0.33 & 10 & 30 & 3 & 0.19 & 0 & 0 & - \\
\hline Table & 10 & 10 & 1 & 1 & 0 & 0 & - & 10 & 30 & 3 & 0.37 & 0 & 0 & - \\
\hline Door handle & 11 & 18 & 2 & 8.28 & 9 & 1 & 5.33 & 12 & 42 & 5 & 0.88 & 0 & 0 & - \\
\hline Light switch & 10 & 10 & 1 & 0.24 & 0 & 0 & - & 10 & 0 & 0 & - & 0 & 0 & - \\
\hline TV remote & 10 & 30 & 3 & 0.49 & 20 & 2 & 0.19 & 10 & 0 & 0 & - & 0 & 0 & - \\
\hline Bed rail & 10 & 40 & 4 & 3.63 & 30 & 3 & 3.07 & 0 & - & - & - & - & - & - \\
\hline
\end{tabular}

As beds are only located in residents' rooms, no bed rail samples were taken from common areas.

answered that they agreed or completely agreed, however this depended on both nursing home and job group $\left(\mathrm{F}_{3,29}=\right.$ $\left.3.05, P=0.044 ; \mathrm{F}_{6,42}=2.50, P=0.045\right)$, where respondents from two of the nursing home mainly reported they neither agreed nor disagreed, but respondents from the two other nursing homes were mainly more worried.

\section{Discussion}

Our study showed that staff members working in nursing homes in The Capital Region of Denmark were not colonised with culturable MRSA, similar to findings in Stockholm, Sweden (Andersson et al., 2012) where no 

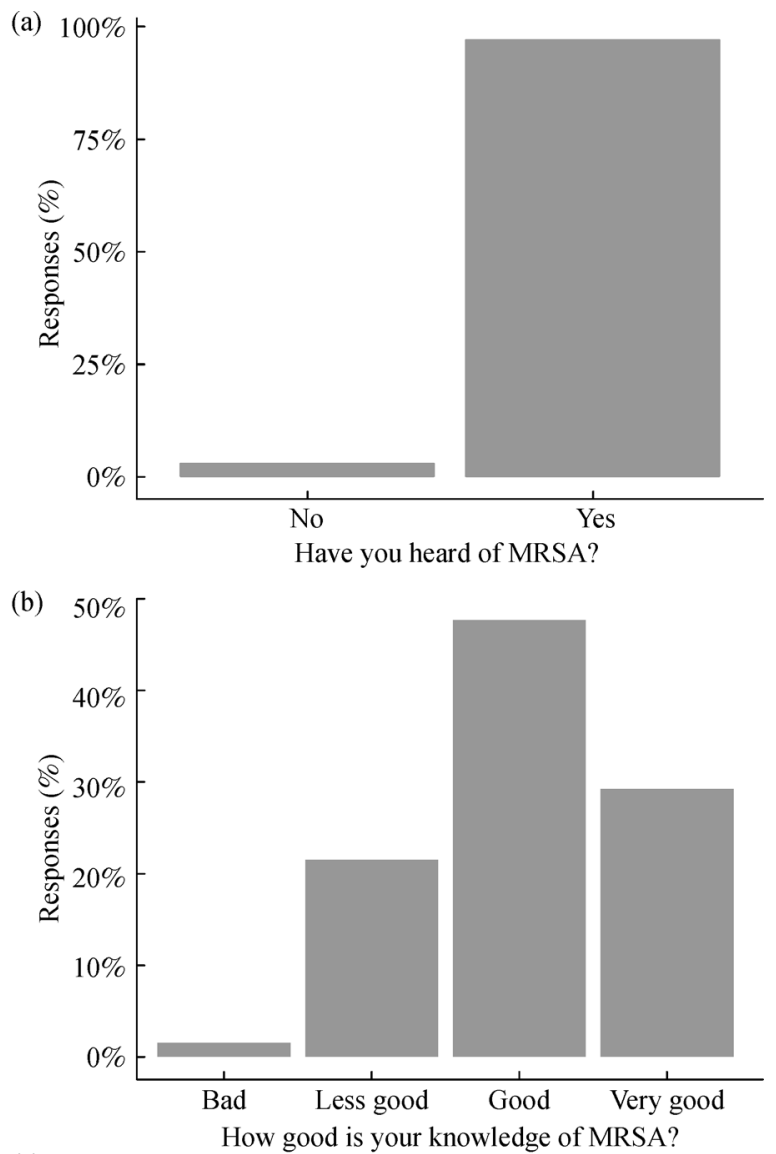

(c)

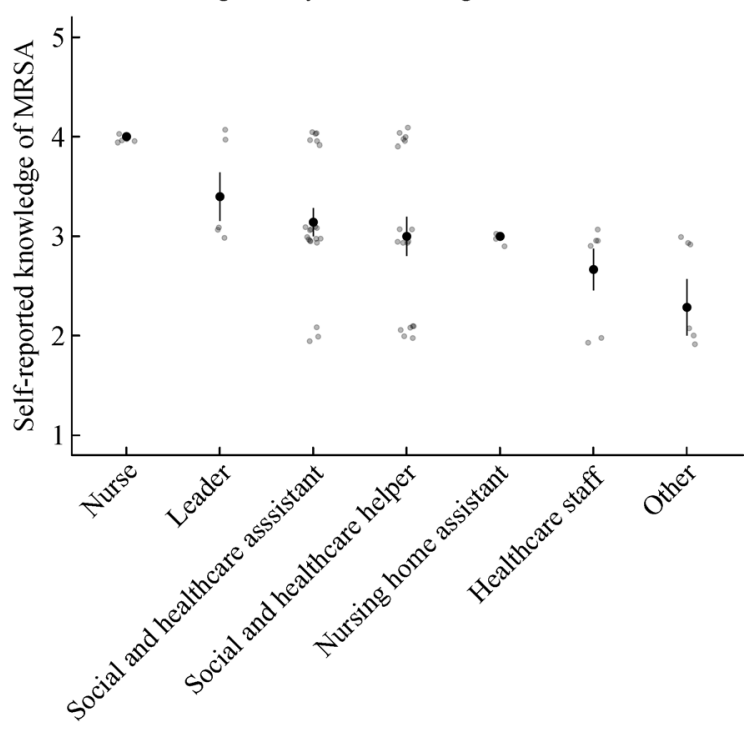

Fig. 2 Self-reported knowledge of methicillin-resistant $S$. aureus (MRSA). Shown are a) whether respondents had heard of MRSA, b) how they assess their knowledge, and c) how their average selfassessed knowledge differs among job groups. Nurses have the longest education, which requires a high school diploma, followed by social and healthcare assistants, social and healthcare helpers and nursing home assistants, and healthcare helper. Nursing home staff are unskilled workers. $1=$ bad, $2=1$ ess bad, $3=\operatorname{good}, 4=$ very good, $5=$ excellent. Shown are means and standard errors.

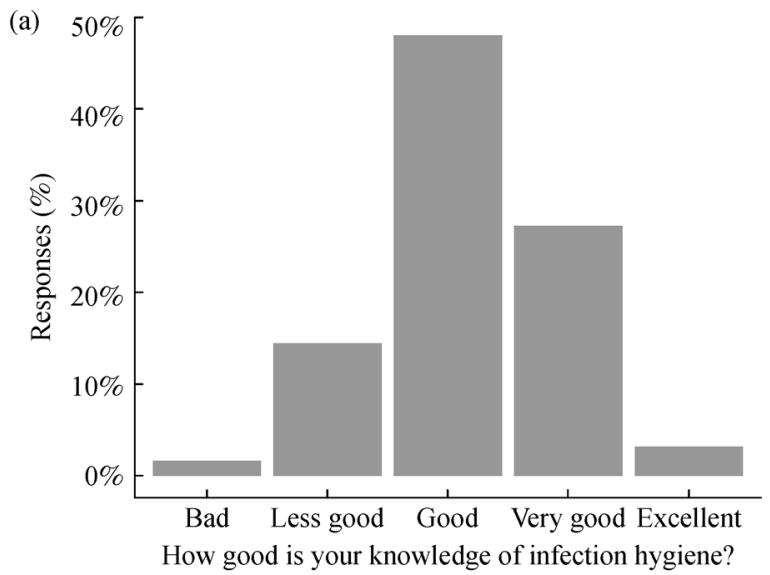

(b)

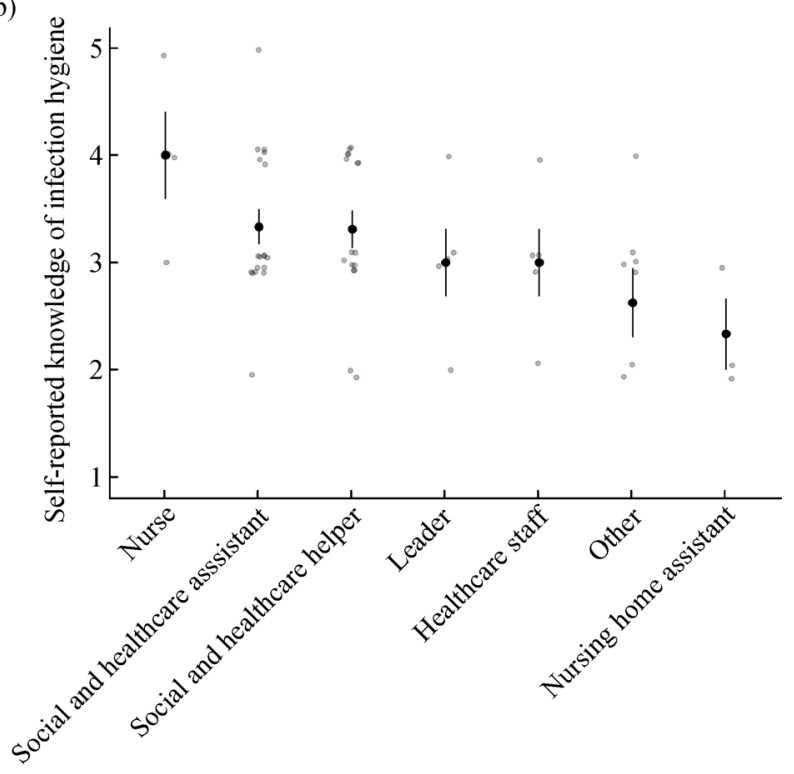

Fig. 3 Self-reported knowledge of infection hygiene. Shown are a) how respondents assess their knowledge, and b) how their average self-assessed knowledge differs among job groups. Nurses have the longest education, which requires a high school diploma, followed by social and healthcare assistants, social and healthcare helpers and nursing home assistants, and healthcare helper. Nursing home staff are unskilled workers. $1=$ bad, $2=$ less bad, $3=$ good, $4=$ very good, $5=$ excellent. Shown are means and standard errors.

MRSA was found among staff members. Our results thereby fall within the lower end of European studies which reported MRSA prevalence among staff ranging from $1.6 \%$ to $7.5 \%$ during non-outbreak times (Baldwin et al., 2009; Monaco et al., 2009; Peters et al., 2017), whereas levels outside Europe has been reported to range from 4\%-90\% (WHO, 2014). The low number found here is positive, since there may typically be a large risk of exposure to staff members in nursing homes, where MRSA can be very prevalent among the residents (Garazi et al., 2009; Murphy et al., 2012), often exceeding levels in hospitals (Honda et al., 2010; Kurup et al., 2010). 
Furthermore, outbreaks among the residents can have severe consequences for both staff and the residents (Koch et al., 2009). However, in S. aureus bacteraemia, MRSA levels are generally low in Scandinavia $<1 \%-5 \%$ (European Centre for Disease Prevention and Control, 2019) and therefore the level of MRSA among nursing home residents is probably much lower in Scandinavia than in the rest of Europe. Future studies may examine whether studying airborne bacterial DNA and using PCR would increase the detection limit of MRSA (e.g. Masclaux et al., 2013), furthermore they may even distinguish between the viable but not culturable fraction (White et al., 2020). In nursing homes in Europe, studies have found MRSA colonisation levels of residents ranging from $0 \%$ to $23.3 \%$ (Baldwin et al., 2009; Monaco et al., 2009; Andersson et al., 2012; Peters et al., 2017). Residents typically have a high risk of contracting MRSA due to e.g. increased use of pharmaceuticals, chronic illness and use of devices such as catheters (Garazi et al., 2009; Wibbenmeyer et al., 2010; Murphy et al., 2012; Peters et al., 2017). However, as the population of seniors is expected to grow in the coming years, it is important to continue to avoid spread to healthcare workers. This is especially important as care workers can act as vectors for the transmission of MRSA to other residents, both as carriers (Albrich and Harbarth, 2008) or through contaminated clothes (Morgan et al., 2012; Roghmann et al., 2015). It is therefore vital that proper hygiene practices are met, not just for the staff members but also for the residents.

Staff members were exposed to MRSA during work in the rooms of the residents colonised with MRSA in two of the five nursing homes, both air samples, sedimented dust, and surface samples. Most studies of nursing homes have determined the exposure to MRSA through screenings of staff and residents (e.g. Baldwin et al., 2009; Andersson et al., 2012), or looked at bioaerosol exposure in hospital or indoor settings (Wilson et al., 2004; Li et al., 2015), but no studies have to our knowledge examined the bioaerosol exposure to MRSA in nursing homes, where unlike in hospitals, MRSA-colonised residents are not isolated. Similar studies have however been done in residential homes where authors have detected MRSA indoors (Madsen et al., 2018) and found higher proportions of antibiotic resistant $S$. aureus indoors than outdoors (Gandara et al., 2006). MRSA can survive on surfaces and the main mode of spread is typically person-to-person contact and contact with contaminated objects and apparel (Neely and Maley, 2000; Calfee et al., 2003; Mitchell et al., 2015; Roghmann et al., 2015), however our findings confirm that MRSA can spread via inhaled particles in the air (Kozajda et al., 2019). This is particularly important, as many respondents in the questionnaire did not know that MRSA could be found in the air.

Staff members were exposed to MRSA in the air during personal care tasks, cleaning of floors, and as general background exposure in the rooms of residents colonised with MRSA. This may highlight tasks that may lead to higher exposure levels, however as MRSA was also detected in the background exposure, it shows that it is crucial that proper precautions are taken in and when leaving the residences of MRSA-colonised individuals. Furthermore, MSSA was found during cleaning of surfaces and fomites and as background exposure in common areas, indicating that with increasing antibiotic resistance, e.g. from abroad, there is the possibility that MRSA could be observed in the places where MSSA was found. Lastly, the MRSA spa types found in air, sedimented dust, and surface samples matched those of the colonised resident, thereby indicating that the MRSA isolates found comes from the resident. Similarly, Madsen et al. (2020) found a considerable overlap between the Staphylococcus species present in surface samples taken within the same environment, and between bacterial species present in surface samples, sedimented dust, and air samples within the same environment

Generally, healthcare personnel in the nursing homes reported to have good knowledge of MRSA and felt safe working with residents who are colonised. However, our findings also show a small portion of staff members who could benefit from further information on the topic, in particular from certain job groups. The jobs groups which generally reported lower knowledge was those of typically shorter educational background, and reported knowledge about MRSA might therefore be linked to the level of education of staff. In addition, approximately one in three staff members at nursing homes report that they are worried of contracting MRSA and one in two are worried about bringing it home to family and acquaintances and to spread it to other residents. Similarly, in a study in Oslo, Norway, Thorstad et al. (2011) reported that half of the nursing home staff asked was concerned about becoming infected with MRSA and the consequences this would have for their own social life, family, economy, and work restriction. This therefore further shows that continued education and awareness of MRSA is important among nursing home staff members.

Most respondents reported that they have good knowledge on infection hygiene, however, less than half had read the Danish Health Authority's guide to the prevention of spread of MRSA (The Danish Health Authority, 2016). In comparison, an audit of healthcare workers in the UK showed that $67 \%$ of respondents had read the UK MRSA policy, though this differed among healthcare groups (Trigg et al., 2008). However, staff may get the proper information elsewhere, for example, as respondents reported here, e.g. from education, colleagues, hygiene nurses, and leaders. Based on the questionnaire it also appears that infection hygiene guidelines are followed well, and most also state that they always or almost always follow the infection hygiene guidelines and that their workplace does. However, improvements could be made in the use and availability of protective eyewear and 
facemasks when there is risks of splashes or sprays of bodily fluids and that cleaning supplies (e.g., vacuum cleaners) are not used both in the residence of MRSA colonised individuals and elsewhere in the nursing home. Andersson et al. (2012) similarly found that personnel at nursing homes in Stockholm, Sweden, reported good knowledge on infection hygiene practices, but when observed by researchers it was found that there were occasional shortcomings in the adherence to the guidelines. Of course, there may be factors that makes full compliance with infection hygiene guidelines hard. For example, respondents point out a lack of cleaning personnel, lack of knowledge of infection hygiene, lack of knowledge of MRSA, poor contact with residents with MRSA due to dementia or mental health, and economic challenges regarding increased care for resident with MRSA as factors contributing to why hygiene guidelines are not always followed.

\section{Concluding remarks}

Our study confirms that MRSA can be found in the air, in sedimented dust and on surfaces, where it may work as an important transmission route. Furthermore, our study indicates that the prevalence of MRSA is low during non-outbreak times among nursing home staff in the Capital Region of Denmark, and that exposure to MRSA is low but confined to the residences of residents with MRSA colonisation. While infection hygiene practices seem to be followed well, our results also show room for improvement. Key areas to highlight based on the questionnaire is the lack of knowledge of aerial spread of MRSA, that MSSA and MRSA give the same infections, the lack of easy access and use of protective face and eyewear during work with risk of splashes, and that a large portion of staff members worry about contracting MRSA and spreading it to family and residents. As knowledge on both MRSA and infection hygiene differs among job groups, it is important that each nursing home continue to educate their personnel on multidrug resistant organisms and proper infection control, including staff members of shorter educational background and perhaps those who are not directly working with care tasks. This may reduce the level of worry about MRSA that staff reported. Maintaining proper hygiene practices and adhering to guidelines is especially important, because failure to do so may cause outbreaks among the residents, which could have severe consequences for both staff and the residents.

Acknowledgements We would like to thank all the participants in the study. We would also like to thank Prof. Dr. Monika Raulf for EDC supply. We acknowledge Margit W. Frederiksen, the National Research Institute of the Working Environment, Denmark, for excellent technical assistance. This work was supported by grant 16-B-0239 from Helsefonden and by the Danish Government through a grant to the FOR-SOSU program (SATS 2004) at the National Research Centre for the Working Environment, Denmark.
Electronic Supplementary Material Supplementary material is available in the online version of this article at https://doi.org/10.1007/s11783-0201333 -y and is accessible for authorized users.

Open Access This article is licensed under a Creative Commons Attribution 4.0 International License, which permits use, sharing, adaptation, distribution and reproduction in any medium or format, as long as you give appropriate credit to the original author(s) and the source, provide a link to the Creative Commons licence, and indicate if changes were made. The images or other third party material in this article are included in the article's Creative Commons licence, unless indicated otherwise in a credit line to the material. If material is not included in the article's Creative Commons licence and your intended use is not permitted by statutory regulation or exceeds the permitted use, you will need to obtain permission directly from the copyright holder. To view a copy of this licence, visit http://creativecommons.org/licenses/by/ $4.0 \%$

\section{References}

Albrich W C, Harbarth S (2008). Health-care workers: Source, vector, or victim of MRSA? Lancet. Infectious Diseases, 8(5): 289-301

Andersson H, Lindholm C, Iversen A, Giske C G, Örtqvist Å, Kalin M, Fossum B (2012). Prevalence of antibiotic-resistant bacteria in residents of nursing homes in a Swedish municipality: Healthcare staff knowledge of and adherence to principles of basic infection prevention. Scandinavian Journal of Infectious Diseases, 44(9): 641649

Baldwin N S, Gilpin D F, Hughes C M, Kearney M P, Gardiner D A, Cardwell C, Tunney M M (2009). Prevalence of methicillin-resistant Staphylococcus aureus colonization in residents and staff in nursing homes in Northern Ireland. Journal of the American Geriatrics Society, 57(4): 620-626

Bartels M D, Larner-Svensson H, Meiniche H, Kristoffersen K, Schønning K, Nielsen J B, Rohde S M, Christensen L B, Skibsted A W, Jarløv J O, Johansen H K, Andersen L P, Petersen I S, Crook D W, Bowden R, Boye K, Worning P, Westh H (2015). Monitoring meticillin resistant Staphylococcus aureus and its spread in Copenhagen, Denmark, 2013, through routine whole genome sequencing. Eurosurveillance, 20(17): 21112

Bates D, Maechler M, Bolker B, Walker S (2014). LME4: linear MixedEffects Models Using Eigen and S4

Böcher S, Middendorf B, Westh H, Mellmann A, Becker K, Skov R, Friedrich A W (2010). Semi-selective broth improves screening for methicillin-resistant Staphylococcus aureus. Journal of Antimicrobial Chemotherapy, 65(4): 717-720

Bradley S F (1999). Methicillin-resistant Staphylococcus aureus. American Journal of Medicine, 106(5 Supplement 1): 2-10

Calfee D P, Durbin L J, Germanson T P, Toney D M, Smith E B, Farr B M (2003). Spread of methicillin-resistant Staphylococcus aureus (MRSA) among household contacts of individuals with nosocomially acquired MRSA. Infection Control and Hospital Epidemiology, 24 (6): 422-426

Calfee D P, Salgado C D, Milstone A M, Harris A D, Kuhar D T, Moody J, Aureden K, Huang S S, Maragakis L L, Yokoe D S (2014). Strategies to prevent methicillin-resistant Staphylococcus aureus transmission and infection in acute care hospitals: 2014 Update. Infection Control and Hospital Epidemiology, 35(7): 772-796 
CDC (2013). Antibiotic Resistance Threats in the United States. Washington, DC: Centers for Disease Control

DANMAP (2018). Use of antimicrobial agents and occurrence of antimicrobial resistance in bacteria from food animals, food and humans in Denmark. Copenhagen: DANMAP

Danmarks Statistik (2020). FOLK1A. Copenhagen: Danmarks Statistik European Centre for Disease Prevention and Control (2019). Surveillance of Antimicrobial Resistance in Europe 2018. Stockholm

Feld L, Bay H, Angen Ø, Larsen A R, Madsen A M (2018). Survival of LA-MRSA in dust from swine farms. Annals of Work Exposures and Health, 62(2): 147-156

Fox J, Weisberg S (2011). An R Companion to Applied Regression. Thousand Oaks: Sage

Gandara A, Mota L C, Flores C, Perez H R, Green C F, Gibbs S G (2006). Isolation of Staphylococcus aureus and antibiotic-resistant Staphylococcus aureus from residential indoor bioaerosols. Environmental Health Perspectives, 114(12): 1859-1864

Garazi M, Edwards B, Caccavale D, Auerbach C, Wolf-Klein G (2009). Nursing homes as reservoirs of MRSA: Myth or reality? Journal of the American Medical Directors Association, 10(6): 414-418

Honda H, Krauss M J, Coopersmith C M, Kollef M H, Richmond A M, Fraser V J, Warren D K (2010). Staphylococcus aureus nasal colonization and subsequent infection in intensive care unit patients: Does methicillin resistance matter? Infection Control and Hospital Epidemiology, 31(6): 584-591

Kenny L C, Aitken R J, Baldwin P E J, Beaumont G C, Maynard A D (1999). The sampling efficiency of personal inhalable aerosol samplers in low air movement environments. Journal of Aerosol Science, 30(5): 627-638

Koch A M, Eriksen H M, Elstrøm P, Aavitsland P, Harthug S (2009). Severe consequences of healthcare-associated infections among residents of nursing homes: A cohort study. Journal of Hospital Infection, 71(3): 269-274

Kozajda A, Jeżak K, Kapsa A (2019). Airborne Staphylococcus aureus in different environments: A review. Environmental Science and Pollution Research International, 26(34): 34741-34753

Kurup A, Chlebicka N, Tan K Y, Chen E X, Oon L, Ling T A, Ling M L, Hong J L G (2010). Active surveillance testing and decontamination strategies in intensive care units to reduce methicillin-resistant Staphylococcus aureus infections. American Journal of Infection Control, 38(5): 361-367

Li X, Qiu Y, Yu A, Shi W, Chen G, Zhang Z, Liu D (2015). Characteristics of airborne Staphylococcus aureus (including MRSA) in Chinese public buildings. Aerobiologia, 31(1): 11-19

Madsen A M, Moslehi-Jenabian S, Islam M Z, Frankel M, Spilak M, Frederiksen M W (2018). Concentrations of Staphylococcus species in indoor air as associated with other bacteria, season, relative humidity, air change rate, and $S$. aureus-positive occupants. Environmental Research, 160: 282-291

Madsen A M, Phan H U T, Laursen M, White J K, Uhrbrand K (2020). Evaluation of methods for sampling of Staphylococcus aureus and other Staphylococcus species from indoor surfaces. Annals of Work Exposures and Health: wxaa080

Masclaux F G, Sakwinska O, Charrière N, Semaani E, Oppliger A (2013). Concentration of airborne Staphylococcus aureus (MRSA and MSSA), total bacteria, and endotoxins in pig farms. Annals of Occupational Hygiene, 57(5): 550-557

Mitchell A, Spencer M, Edmiston C Jr (2015). Role of healthcare apparel and other healthcare textiles in the transmission of pathogens: A review of the literature. Journal of Hospital Infection, 90(4): 285292

Monaco M, Bombana E, Trezzi L, Regattin L, Brusaferro S, Pantosti A, Goglio A (2009). Meticillin-resistant Staphylococcus aureus colonising residents and staff members in a nursing home in Northern Italy. Journal of Hospital Infection, 73(2): 182-184

Morgan D J, Rogawski E, Thom K A, Johnson J K, Perencevich E N, Shardell M, Leekha S, Harris A D (2012). Transfer of multidrugresistant bacteria to healthcare workers' gloves and gowns after patient contact increases with environmental contamination. Critical Care Medicine, 40(4): 1045-1051

Murphy C R, Quan V, Kim D, Peterson E, Whealon M, Tan G, Evans K, Meyers H, Cheung M, Lee B Y, Mukamel D B, Huang S S (2012). Nursing home characteristics associated with methicillin-resistant Staphylococcus aureus (MRSA) Burden and Transmission. BMC Infectious Diseases, 12(1): 269

Neely A N, Maley M P (2000). Survival of enterococci and staphylococci on hospital fabrics and plastic. Journal of Clinical Microbiology, 38(2): 724-726

Peters C, Dulon M, Kleinmüller O, Nienhaus A, Schablon A (2017). MRSA prevalence and risk factors among health personnel and residents in nursing homes in Hamburg, Germany: A cross-sectional study. PLoS One, 12(1): e0169425

R. Core Team (2019). R: A Language and Environment for Statistical Computing. Vienna: R Foundation for Statistical Computing

Roghmann M C, Johnson J K, Sorkin J D, Langenberg P, Lydecker A, Sorace B, Levy L, Mody L (2015). Transmission of methicillinresistant Staphylococcus aureus (MRSA) to healthcare worker gowns and gloves during care of nursing home residents. Infection Control and Hospital Epidemiology, 36(9): 1050-1057

Stone N D, Lewis D R, Lowery H K, Darrow L A, Kroll C M, Gaynes R P, Jernigan J A, Mcgowan J E Jr, Tenover F C, Richards C L Jr (2008). Importance of bacterial burden among methicillin-resistant Staphylococcus aureus carriers in a long-term care facility. Infection Control and Hospital Epidemiology, 29(2): 143-148

Sundheds- Og Ældreministeriet (2016). National Survey of the Conditions in Care Centers. København K: Sundheds- Og Ældreministeriet

The Danish Health Authority (2016). Guidance on preventing the spread of MRSA. København S, Denmark: The Danish Health Authority

Thorstad M, Sie I, Andersen B M (2011). MRSA: A challenge to Norwegian nursing home personnel. Interdisciplinary Perspectives on Infectious Diseases, 2011: 197683

Trigg D, Timmons S, Pynegar C (2008). An audit of healthcare workers' knowledge of meticillin resistant Staphylococcus aureus (MRSA) against current infection control standards. British Journal of Infection Control, 9(1): 30-33

White J K, Nielsen J L, Larsen C M, Madsen A M (2020). Impact of dust on airborne Staphylococcus aureus' viability, culturability, inflammogenicity, and biofilm forming capacity. International Journal of Hygiene and Environmental Health, 230: 113608 
WHO (2014). Antimicrobial Resistance: Global Report on Surveillance. Geneva: World Health Organization

Wibbenmeyer L, Williams I, Ward M, Xiao X, Light T, Latenser B, Lewis R, Kealey G P, Herwaldt L (2010). Risk factors for acquiring vancomycin-resistant Enterococcus and methicillin-resistant Staphylococcus aureus on a burn surgery step-down unit. Journal of Burn
Care \& Research; Official Publication of the American Burn Association, 31(2): 269-279

Wilson R D, Huang S J, Mclean A S (2004). The correlation between airborne methicillin-resistant Staphylococcus aureus with the presence of MRSA colonized patients in a general intensive care unit. Anaesthesia and Intensive Care, 32(2): 202-209 